\title{
Neutrophil killing of Staphylococcus aureus in diabetes, obesity and metabolic syndrome: a prospective cellular surveillance study
}

\author{
Ingrid Lea Scully ${ }^{1}$, Lisa Kristin McNeil ${ }^{1}$, Sudam Pathirana' ${ }^{1}$ Christine Lee Singer ${ }^{1}$, Yongdong Liu', \\ Stanley Mullen ${ }^{1}$, Douglas Girgenti ${ }^{1}$, Alejandra Gurtman' ${ }^{1}$, Michael W. Pride ${ }^{1}$, Kathrin Ute Jansen ${ }^{1}$, Paul L. Huang ${ }^{2}$ \\ and Annaliesa S. Anderson ${ }^{1 *}$
}

\begin{abstract}
Background: Obesity, metabolic syndrome (MetS), and diabetes are frequent in surgical populations and can enhance susceptibility to postoperative surgical site infections. Reduced neutrophil function has been linked with diabetes and risk of Staphylococcus aureus infection. Therefore, neutrophil function in diabetic and obese subjects $( \pm$ MetS) was assessed in this prospective serological and cellular surveillance study to determine whether vaccines administered to protect against infections after surgery could be effective in these populations.

Methods: Neutrophil function (chemotaxis, phagocytosis, and opsonophagocytic killing of S. aureus) was assessed in subjects classified according to diabetes status, body mass index, and presence/absence of MetS. Neutrophils were characterized within functional subsets by flow cytometry. A serologic assay was used to measure baseline antibody presence to each antigen in SA4Ag: capsular polysaccharide (CP) type 5, CP8, recombinant mutant Clumping factor A (rmClfA), and recombinant Manganese transport protein C ( $\mathrm{rMntC}$ ).

Results: Neutrophil function was similar for comorbid and healthy cohorts, with no significant between-group differences in cell counts, migration, phagocytosis ability, neutrophil subset proportions, and S. aureus killing ability when neutrophils were isolated 3-6 months apart (Visit $1[n=90]$ and Visit $2[n=70]$ ) and assessed. Median pre-existing antibody titers to CP5, CP8, and rmClfA were comparable for all cohorts (insufficient subjects with rMntC titers for determination).
\end{abstract}

Conclusions: MetS, diabetes, and obesity do not impact in vitro neutrophil function with regard to $S$. aureus killing, suggesting that if an effective $S$. aureus vaccine is developed it may be effective in individuals with these comorbidities.

Keywords: Diabetes, Immune function, Metabolic syndrome, Neutrophils, Obesity, Staphylococcus aureus, Vaccine

\section{Background}

Obesity, metabolic syndrome, and diabetes are frequent comorbid disorders in surgical populations, which may enhance patients' susceptibility to postoperative surgical

\footnotetext{
${ }^{*}$ Correspondence: annaliesa.anderson@pfizer.com

1 Pfizer Vaccine Research and Development, 401 North Middletown Rd, Pearl River, NY 10965, USA

Full list of author information is available at the end of the article
}

site infections. The Gram-positive bacterium Staphylococcus aureus is a bacterial pathogen that frequently causes healthcare-associated infections, especially among adults undergoing major surgery. Invasive staphylococcal infections are more prevalent in patients with diabetes and obesity than in those without, and are associated with a poor outcome [1-3].

The underlying mechanisms linking these comorbidities to $S$. aureus infection are not fully defined, but 
may be linked to impairment in several aspects of the immune response to bacterial infections. These aspects include impaired healing, fibroblast and epidermal cell dysfunction, impaired angiogenesis, damage from reactive oxygen species and advanced glycation end products, and decreased host immune resistance [4]. The primary defense against gram-positive pathogens such as $S$. aureus is engulfment and oxidative killing by neutrophils, a process that is dependent on tissue oxygen tension. Obese patients have decreased tissue oxygen tension and poor blood supply. In those undergoing surgery, this presents a particular problem at the surgical incision site, and increases the risk for surgical site infections [5]. Decreased serum and tissue concentrations of prophylactic antibiotics and increased rates of perioperative hyperglycemia [6] may further increase the risk of postoperative infection.

There are reports of impaired bactericidal functions, including phagocytosis, adhesion to endothelium, and chemotaxis by neutrophils in patients with diabetes [7-9]. Conversely, other reports have failed to show significant differences in immunological function in patients with diabetes versus healthy patients [10]. Impaired peripheral blood mononuclear cell (PBMC) function, decreased lymphocyte proliferation, and altered peripheral cytokine levels have also been reported in patients with obesity [11].

Distinct subsets of circulating neutrophils in peripheral blood, based on maturity, have been described during acute systemic inflammation. These cells may also differ in their functional capacities, such as chemotaxis and adhesion characteristics $[12,13]$.

In diabetic mouse models, chronic wounds are characterized by the presence of elevated cytokines, increased neovascularization, and infiltration of inflammatory cells such as macrophages and neutrophils [14, 15]. Manifestations of neutrophil dysfunction such as decreased phagocytosis, superoxide production, and killing activity of $S$. aureus have also been observed in diabetic $d b / d b$ mice [16].

The challenges of controlling S. aureus infections as well as the associated treatment costs are exacerbated by increasing rates of resistance to available antibiotics. Currently, there is no licensed, prophylactic $S$. aureus vaccine that can prevent postoperative infections in high-risk patients. Such a vaccine could help to reduce the incidence of $S$. aureus disease and the associated morbidity, mortality, and cost.

The results of previous unsuccessful vaccine development programs and preclinical research programs indicate that an effective vaccine against $S$. aureus should contain several antigens targeting multiple virulence mechanisms [17, 18]. A prophylactic $S$. aureus 4-antigen
(SA4Ag) vaccine is under evaluation in a Phase IIb trial (NCT02388165) in adults undergoing elective spinal fusion. The SA4Ag vaccine is composed of 2 capsular polysaccharide conjugates $\left(\mathrm{CP} 5-\mathrm{CRM}_{197}\right.$ and CP8-CRM $\left.{ }_{197}\right)$, recombinant surface protein clumping factor $\mathrm{A}$ (rmClfA) and recombinant $\mathrm{MntC}(\mathrm{rMntC})$ from the ligand binding portion of lipoprotein manganese transporter C. rMntC facilitates $S$. aureus survival in vivo, and preclinical evaluations supported the addition of $\mathrm{rMntC}$ to target this bacterial virulence factor [19].

In a dose-ranging, Phase I, randomized, placebo-controlled, clinical study in healthy adults, the precursor to the SA4Ag vaccine, a non-adjuvanted 3-antigen $S$. aureus vaccine (SA3Ag), which included CP5-CRM ${ }_{197}$, CP8-CRM ${ }_{197}$, and rmClfA, was found to induce robust, functional (bacteria-killing) immune responses, with an acceptable safety and tolerability profile [20]. These immune responses were maintained through 12 months after a single vaccination [20]. Based on the immunogenicity and safety findings of this study, $30 \mu \mathrm{g} \mathrm{CP5-}$ $\mathrm{CRM}_{197}, 30 \mu \mathrm{g}$ CP8-CRM ${ }_{197}$, and $60 \mu \mathrm{g}$ rmClfA were selected for inclusion in the SA4Ag formulation. Two Phase I/Phase II studies in healthy adults showed that SA4Ag was well tolerated and induced rapid and robust functional immune responses to all 4 antigens after a single vaccination. Antibody levels remained substantially above pre-vaccination levels through month 12 following vaccination $[21,22]$. The dose level of $\mathrm{rMntC}$ for inclusion in the final formulation of SA4Ag was $200 \mu \mathrm{g}$, based on dose level-dependent immune responses to $\mathrm{rMntC}$ and the overall safety profile shown in these studies [21, 22].

Neutrophils provide an essential primary defense against $S$. aureus, and are therefore likely to contribute to vaccine-mediated, protective, immune responses. To provide a better understanding of the likelihood that an $S$. aureus vaccine could be effective in subjects with diabetes, obesity, and metabolic syndrome (MetS), neutrophil functions in these patient populations were evaluated in this prospective serological and cellular surveillance study. The primary objectives of this study were to descriptively compare neutrophil function in six cohorts of adult subjects: (1) adults with well-controlled diabetes mellitus, (2) adults with poorly controlled (hemoglobin A1c (HbA1c) $\geq 10 \%$ ) diabetes mellitus, (3) adults with morbid obesity (body mass index, BMI $\geq 40 \mathrm{~kg} /$ $\mathrm{m}^{2}$ ), (4) obese adults (BMI $\geq 30 \mathrm{~kg} / \mathrm{m}^{2}$ ) with MetS, (5) obese adults without MetS, and (6) healthy patients with normal BMI $\left(18.5-24.9 \mathrm{~kg} / \mathrm{m}^{2}\right)$ and without diabetes mellitus.

Secondary objectives were to descriptively compare immune function in: adults with well-controlled $(\mathrm{HbA} 1 \mathrm{c}<7 \%)$ and poorly-controlled $(\mathrm{HbA} 1 \mathrm{c} \geq 10 \%)$ 
diabetes mellitus; adults without diabetes mellitus and with well-controlled diabetes mellitus (HbA1c < 7\%); obese adults (BMI 30 to $<40 \mathrm{~kg} / \mathrm{m}^{2}$ ) and morbidly obese adults $\left(B M I \geq 40 \mathrm{~kg} / \mathrm{m}^{2}\right)$. Neutrophil function was evaluated with regard to chemotactic migration, bacterial phagocytosis and opsonophagocytosis (bacterial killing). Neutrophil subsets (normal, killer, and suppressor) and plasma antibody titers were also assessed.

\section{Methods}

\section{Study design and patient selection}

This was an exploratory clinical research collaboration between Massachusetts General Hospital and the Pfizer Vaccine Research and Development Unit. All subjects were interviewed and received physical examinations and laboratory testing. Written informed consent was obtained from all participants before study procedures were initiated. The study was approved by the Institutional Review Board of the Massachusetts General Hospital.

Subjects were not vaccinated for this study. Two fasting blood draws (Visit 1 and Visit 2) were taken approximately 3-6 months apart for immune function assays. At Visits 1 and 2, $50 \mathrm{~mL}$ blood was drawn for evaluation of immune function, and $10 \mathrm{~mL}$ blood was drawn for fasting lipid profile, fasting blood glucose, $\mathrm{C}$-reactive protein (CRP), and HbA1c. Based on the results from these evaluations at Visit 1 blood draw, all subjects (or a subset) from each cohort were selected for Visit 2 blood draw.

In the main analysis, MetS was diagnosed according to the National Cholesterol Education Program Adult Treatment Panel III (NCEP ATPIII) criteria when any 3 or more of the 5 criteria below were met [23]:

1. Waist circumference $>35 \mathrm{in}$. in women or $>40 \mathrm{in}$. in men.

2. Triglycerides $>150 \mathrm{mg} / \mathrm{dL}$.

3. HDL-cholesterol $<50 \mathrm{mg} / \mathrm{dL}$ in women or $<40 \mathrm{mg} /$ $\mathrm{dL}$ in men.

4. Blood pressure $>130 / 85 \mathrm{mmHg}$.

5. Fasting glucose $>100 \mathrm{mg} / \mathrm{dL}$.

\section{Inclusion criteria}

Subjects were included in the study if they were aged 30-75 years and fulfilled any of the following 6 cohort groups; the target was at least 12 subjects per subgroup, based on the following criteria and described in Fig. 1.

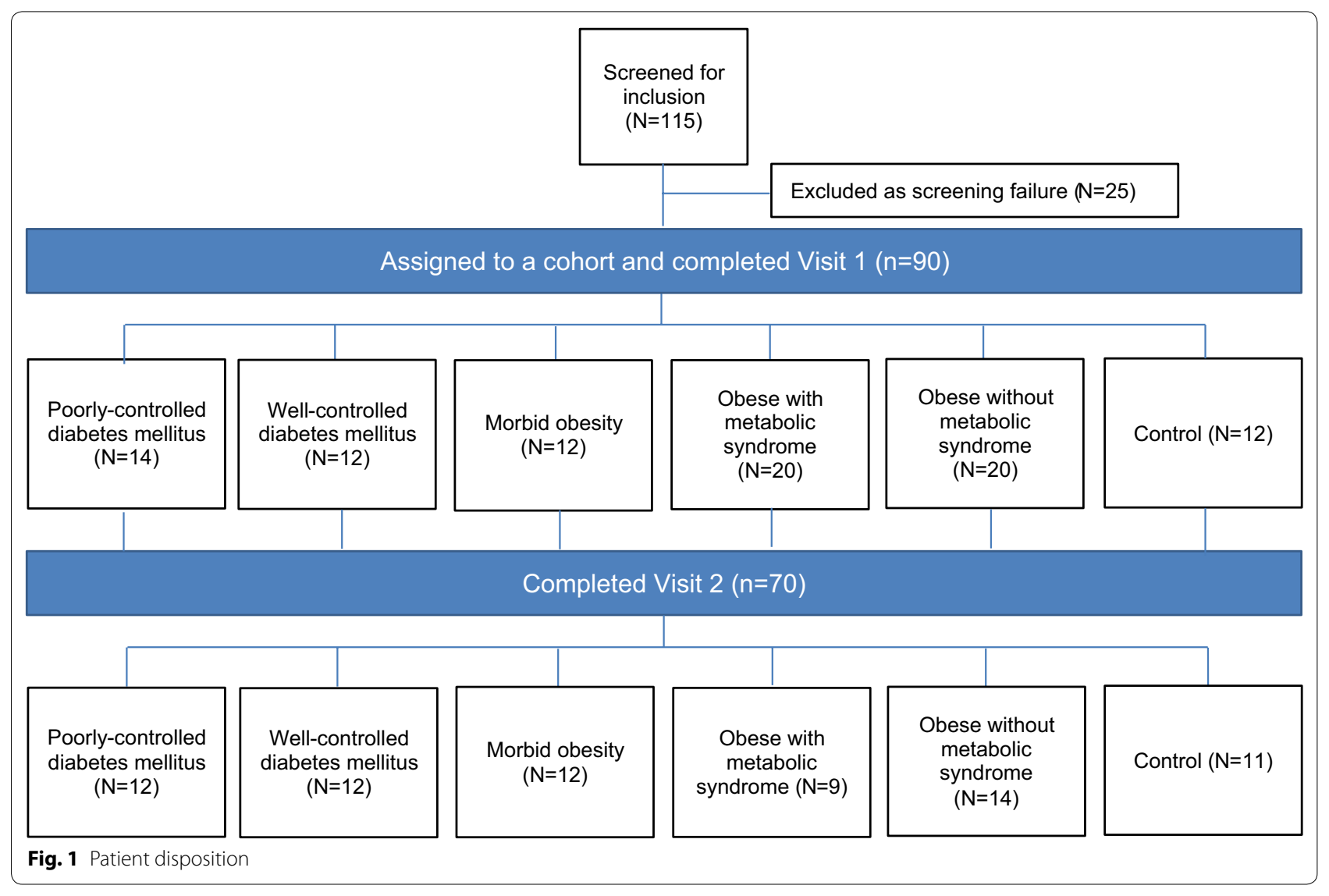


Poorly controlled diabetes mellitus cohort: 12 subjects with diabetes mellitus and HbA1c $\geq 10 \%$ (BMI $<30 \mathrm{~kg} /$ $\mathrm{m}^{2}$ ). Priority was given to subjects with HbA1c $\geq 10 \%$ and BMI $<30 \mathrm{~kg} / \mathrm{m}^{2}$. Where sufficient subjects presenting with $\mathrm{HbA1c} \geq 10 \%$ could not be identified, the investigator preferentially selected the candidate subjects with the highest HbA1c levels $\geq 8.5 \%$ to fill the cohort. When sufficient subjects with a BMI $<30 \mathrm{~kg} /$ $\mathrm{m}^{2}$ could not be identified, subjects were prioritized by the lowest BMI values $<40 \mathrm{~kg} / \mathrm{m}^{2}$ to fill the cohort.

Well controlled diabetes mellitus cohort: 12 subjects with diabetes mellitus and HbA1c $<7 \%(\mathrm{BMI}<30 \mathrm{~kg} /$ $\mathrm{m}^{2}$ ).

Morbid obesity cohort: 12 subjects with morbid obesity (BMI $\geq 40 \mathrm{~kg} / \mathrm{m}^{2}$ ), no diabetes mellitus and $\mathrm{HbA} 1 \mathrm{c}<6 \%$, or well-controlled diabetes and HbA1c $<7 \%$.

Obese with MetS cohort: 12 subjects with BMI 30 to $<40 \mathrm{~kg} / \mathrm{m}^{2}$ and a diagnosis of MetS, no diabetes mellitus and $\mathrm{HbA} 1 \mathrm{c}<6 \%$, or well-controlled diabetes and $\mathrm{HbA} 1 \mathrm{c}<7 \%$.

Obese without MetS cohort: 12 subjects with BMI 30 to $<40 \mathrm{~kg} / \mathrm{m}^{2}$, with clinical assessments and laboratory data not consistent with MetS, no diabetes mellitus and $\mathrm{HbA} 1 \mathrm{c}<6 \%$, or well-controlled diabetes and HbA1c $<7 \%$. When recruiting subjects to this cohort, priority was given to subjects with no diabetes mellitus and HbA1c $<6 \%$.

Healthy patient control cohort: 12 subjects without a diagnosis of diabetes mellitus and HbA1c $<6.0 \%$, without MetS, and with normal BMI $\left(18.5-24.9 \mathrm{~kg} / \mathrm{m}^{2}\right)$.

\section{Exclusion criteria}

Exclusion conditions included: inability to give blood, self-reported diseases (hepatitis B, hepatitis C, human immunodeficiency virus [HIV]), end-stage renal or liver disease, or malignancy that was treated), immunocompromised status, other severe acute or chronic medical or psychiatric condition or laboratory abnormality that may increase the risk associated with study participation or may interfere with the interpretation of study, participation in other interventional or investigational studies within 30 days before the current study through study completion, receipt of blood products or immunoglobulins within 6 months, and receipt of antibiotic therapy within $72 \mathrm{~h}$ of blood draw, pregnancy, or surgery within 30 days of blood draw.

\section{Immunogenicity measurements}

Neutrophils and peripheral blood mononuclear cells (PBMCs) were isolated from collected fasting blood samples. Briefly, after Ficoll-Paque (Fisher) centrifugation of peripheral blood, neutrophils and PBMCs were separated from erythrocytes by $3 \%$ dextran-500 (Sigma) density-gradient sedimentation. Isolated cells were resuspended in Hank's Balanced Salt Solution (Cellgro) for cell counts. The in vitro assays described below were used to measure functional responses to $S$. aureus. Isolated PBMC and neutrophil cell counts were expressed as cell count $\times 10^{7}$.

\section{Chemotaxis assay}

The chemotaxis assay measured in vitro migration of isolated neutrophils towards the test chemoattractants, $\mathrm{N}$-formyl-methionyl-leucyl-phenylalanine (fMLP), interleukin (IL)-8, complement component C5a, fetal bovine serum (FBS), and RPMI media. Results were expressed as $\%$ migration, calculated as the proportion of signal in the test wells compared to directly lysed input cell control, which was set at $100 \%$. Chemotaxis was measured using a 96-well cell migration assay kit (Cell BioLabs, cat \# CBA104) with a polycarbonate membrane plate to determine the migratory properties of the cells. Any migratory cells were first dissociated from the membrane, then lysed and detected with CyQuant GR Dye provided with the kit, per the manufacturer's instructions.

\section{Phagocytosis assay}

The phagocytosis assay (pHrodo assay) measured in vitro neutrophil uptake of opsonized S. aureus. Assay results were expressed as \% phagocytosis, representing the \% of cells that had fluorescent signal. The assay utilizes a $\mathrm{pH}$-sensitive, rhodamine-based $\mathrm{pHrodo}^{\mathrm{TM}}$ Red dye (Life Technologies, cat \# P3660) to detect neutrophil phagocytic functionality. pHrodo fluoresces when exposed to low $\mathrm{pH}(<4.0)$, which is required for bactericidal functions and antigen processing and presentation. Phagocytosis is therefore quantifiable when the phagosome forms and acidifies around ingested pHrodo-labeled S. aureus, minimizing high background fluorescence of cell-bound but uningested bacteria [24, 25]. The opsonizing agents were individual (autologous) plasma samples, normal human sera, and human CP8 immune sera. Uptake in the absence of added serum was also tested as a control (no opsonization).

\section{Neutrophil phenotype subset assay}

The isolated neutrophils were sorted into three different subsets based on CD16 and CD62L expression using flow cytometry: normal (CD16 ${ }^{\text {bright }}$ CD62 $\mathrm{L}^{\text {bright }}$ ), suppressor (CD16 ${ }^{\text {bright }}$ CD62 $\mathrm{L}^{\text {dim }}$ ), and killer (CD16 ${ }^{\text {dim }}$ CD62 $\mathrm{L}^{\text {bright }}$ ) neutrophils, as previously described [13]. CD47 expression was also measured. Results were expressed as \% cells for the subsets, based on the \% of cells falling into a flow cytometric gate for each subset, and mean fluorescence intensity (MFI) for the CD47 assay. 


\section{Antibody-mediated opsonophagocytic assay}

Functional immune responses were determined in opsonophagocytic activity (OPA) killing assays with isolated neutrophils and clinical $S$. aureus strains expressing CP8. Neutrophils were tested with 3 different human CP8 immune sera (high-titered, medium-titered, and low-titered sera) [26]. Results were expressed as OPA titers, defined as the serum dilution that killed $50 \%$ of the input bacteria in the assay in a complement and effector cell dependent manner.

\section{Competitive Luminex immunoassay (CLIA)}

A 4-plex competitive Luminex ${ }^{\circledR}$ (Luminex Corporation, Austin, TX, USA) immunoassay (cLIA) that measures the ability of serum immunoglobulin to compete with the binding of antigen-specific monoclonal antibodies to antigen-coated microspheres was used to detect the preexisting CP5, CP8, ClfA, and rMntC antibody titers in the selected patient cohorts [20,27]. Results were determined against a reference standard and expressed as cLIA titers.

\section{Alternative AHA/NHLBI diagnostic criteria for metabolic syndrome}

The diagnostic criteria outlined by the 2005 American Heart Association/National Heart, Lung, and Blood Institute (AHA/NHLBI) for MetS [28] was used to analyse the subject data in $a$ post hoc analysis. The main difference between the AHA/NHLBI and the NCEP ATPIII criteria is that according to the AHA/NHLBI criteria definition, MetS is diagnosed if an individual has normal laboratory/blood pressure values but is receiving drug treatment for the condition while the NCEP ATPIII criteria does not include these patients.

Using the AHA/NHLBI criteria, MetS was diagnosed when any three or more of the following criteria were met [28]:

1. Waist circumference $\geq 35 \mathrm{in}$. in women or $\geq 40 \mathrm{in}$. in men.

2. Triglycerides $\geq 150 \mathrm{mg} / \mathrm{dL}$ or on drug treatment for elevated triglycerides.

3. HDL-cholesterol $<50 \mathrm{mg} / \mathrm{dL}$ in women or $<40 \mathrm{mg} /$ $\mathrm{dL}$ in men or on drug treatment for reduced HDLcholesterol.

4. Blood pressure $\geq 130 / 85 \mathrm{mmHg}$ or on antihypertensive drug treatment (patient with a history of hypertension).

5. Fasting glucose $\geq 100 \mathrm{mg} / \mathrm{dL}$ or on drug treatment for elevated glucose.

\section{Statistical analysis}

For continuous variables, the number (n), mean, median, standard deviation (SD), minimum ( $\mathrm{min}$ ) and maximum
( $\max )$ for normally distributed endpoints or $\mathrm{n}$, geometric mean, min, max, \% relative standard deviation (RSD) and 95\% confidence intervals (CI) for log-normally distributed endpoints were summarized using descriptive statistics. For categorical variables, n, percentage, and total (N) were also summarized using descriptive statistics. The descriptive statistics as detailed above were used for all neutrophil analyses.

\section{Results}

\section{Subject disposition and characteristics}

A total of 115 participants were screened, of whom 90 were assigned to a cohort and completed Visit 1 , and 70 completed Visit 2 (Fig. 1). The remaining 20 were unable to be scheduled for Visit 2. The demographic characteristics of all 6 cohorts were comparable except for the gender distribution (Table 1). There were similar proportions of males and females in the well-controlled diabetes $(50 \%)$ and morbidly obese (50\%) cohorts; more males in the poorly-controlled diabetes (71\%: 29\%), obese with MetS (70\%: 30\%) and obese without MetS (60\%: 40\%) cohorts; and more females in the healthy patient control cohort (33\%: 67\%). The mean age across all cohorts was 58.9 years and the majority were white (Table 1 ).

Participants were separated into cohorts (poorly-controlled diabetes mellitus, well-controlled diabetes mellitus, morbid obesity, obese with MetS, obese without MetS) according to BMI and HbA1c constraints.

The mean $\mathrm{BMI}( \pm \mathrm{SD})$ for the morbidly obese cohort was $45.2 \pm 9.12 \mathrm{~kg} / \mathrm{m}^{2}$; obese with MetS was $33.8 \pm 1.85 \mathrm{~kg} /$ $\mathrm{m}^{2}$; obese with no MetS was $34.4 \pm 2.83 \mathrm{~kg} / \mathrm{m}^{2}$; poorlycontrolled diabetes mellitus was $30.4 \pm 4.28 \mathrm{~kg} / \mathrm{m}^{2}$; wellcontrolled diabetes mellitus was $26.5 \pm 2.33 \mathrm{~kg} / \mathrm{m}^{2}$, and the healthy patient group was $22.1 \pm 1.27 \mathrm{~kg} / \mathrm{m}^{2}$.

The mean HbA1c level was $10.1 \%$ in the poorly-controlled diabetes cohort, $6.3 \%$ in the well-controlled diabetes cohort, $5.6 \%$ in the morbidly obese, $5.9 \%$ in the obese with MetS, $5.5 \%$ in the obese without MetS, and 5.6\% in the healthy patient cohort. Mean fasting blood glucose followed a similar pattern. In addition to those in the obese with MetS cohort, $85.7 \%$ in the poorly-controlled diabetes cohort and $58.3 \%$ each in the well-controlled diabetes and morbidly obese cohorts were also diagnosed with MetS.

\section{Immunogenicity results}

No significant differences were noted between Visit 1 and Visit 2 for all parameters assessed; therefore data from both visits were pooled for all results.

\section{PBMC and neutrophil cell counts}

The average cell count of both visits ranged from 2.7 to $3.4 \times 10^{7}$ for PBMCs and 7.1 to $12.1 \times 10^{7}$ for 
Table 1 Subject demographics

\begin{tabular}{|c|c|c|c|c|c|c|}
\hline \multicolumn{7}{|l|}{ Cohort } \\
\hline Characteristics & $\begin{array}{l}\text { Poorly-controlled } \\
\text { diabetes mellitus } \\
(\mathrm{N}=14)\end{array}$ & $\begin{array}{l}\text { Well-controlled } \\
\text { diabetes mellitus } \\
(\mathrm{N}=12)\end{array}$ & $\begin{array}{l}\text { Morbid obesity } \\
(N=12)\end{array}$ & $\begin{array}{l}\text { Obese with meta- } \\
\text { bolic syndrome } \\
(\mathrm{N}=20)\end{array}$ & $\begin{array}{l}\text { Obese with- } \\
\text { out metabolic } \\
\text { syndrome }(N=20)\end{array}$ & Control $(\mathrm{N}=12)$ \\
\hline \multicolumn{7}{|l|}{ Sex, n (\%) } \\
\hline Male & $10(71.4)$ & $6(50.0)$ & $6(50.0)$ & $14(70.0)$ & $12(60.0)$ & $4(33.0)$ \\
\hline Female & $4(28.6)$ & $6(50.0)$ & $6(50.0)$ & $6(30.0)$ & $8(40.0)$ & $8(66.7)$ \\
\hline \multicolumn{7}{|l|}{ Race, n (\%) } \\
\hline White & $10(71.4)$ & $9(75.0)$ & $9(75.0)$ & $18(90.0)$ & $16(80.0)$ & $10(83.3)$ \\
\hline $\begin{array}{c}\text { Black or African } \\
\text { American }\end{array}$ & $3(21.4)$ & $3(25.0)$ & $3(25.0)$ & $2(10.0)$ & $4(20.0)$ & $2(16.7)$ \\
\hline Asian & $1(7.1)$ & $1(2.6)$ & $1(2.6)$ & $0(0.0)$ & $0(0.0)$ & $0(0.0)$ \\
\hline \multicolumn{7}{|l|}{ Ethnicity, n (\%) } \\
\hline Hispanic or latino & & & & $1(5.0)$ & & \\
\hline $\begin{array}{l}\text { Non-hispanic/ } \\
\text { latino }\end{array}$ & $14(100.0)$ & $12(100.0)$ & $12(100.0)$ & $19(95.0)$ & $20(100.0)$ & $12(100.0)$ \\
\hline \multicolumn{7}{|l|}{ Age at entry (years) } \\
\hline Mean (SD) & $60.6(7.11)$ & $64.0(8.10)$ & $57.1(8.82)$ & $59.1(10.23)$ & $52.0(10.71)$ & $60.9(11.37)$ \\
\hline Median (min, max) & $62.0(47,72)$ & $66.0(48,73)$ & $56.0(45,70)$ & $59.0(41,74)$ & $51.5(33,72)$ & $65.5(34,72)$ \\
\hline
\end{tabular}

neutrophils. The $95 \%$ CIs of the 6 cohorts overlapped for both PBMCs and neutrophil counts. Median PBMC and neutrophil cell counts were comparable for all 6 cohorts (Figs. 2, 3). These results indicate that there was no evidence that the number of PBMCs or neutrophils were overtly different between the cohorts, except for the poorly controlled diabetes group, which had a trend for a higher median number of neutrophils.

\section{Chemotaxis}

The average percentage migration at both visits ranged from 17 to $25 \%$ for fMLP, from 25 to $36 \%$ for IL-8, from 20 to $29 \%$ for C5a, and from 83 to $103 \%$ for FBS (positive control chemoattractant). The $95 \%$ CIs of the 6 cohorts overlapped for fMLP, IL-8, C5a, and FBS, indicating no difference in \% migration between the cohorts for any of the chemoattractants tested. The median migration for all 6 cohorts was comparable for the chemoattractants tested (Fig. 4). These results indicate that there was no evidence for differences in neutrophil migration rate towards chemoattractants fMLP, IL-8, and C5a for all 6 cohorts.

\section{Phagocytosis}

The average \% phagocytosis determined in both visits ranged from 50 to $64 \%$ for individual (autologous) plasma, and from 63 to $72 \%$ for the same exogenously provided CP8 immune sera. The 95\% CIs of the 6 cohorts overlapped for individual autologous plasma samples, normal human sera, and CP8 immune sera, indicating

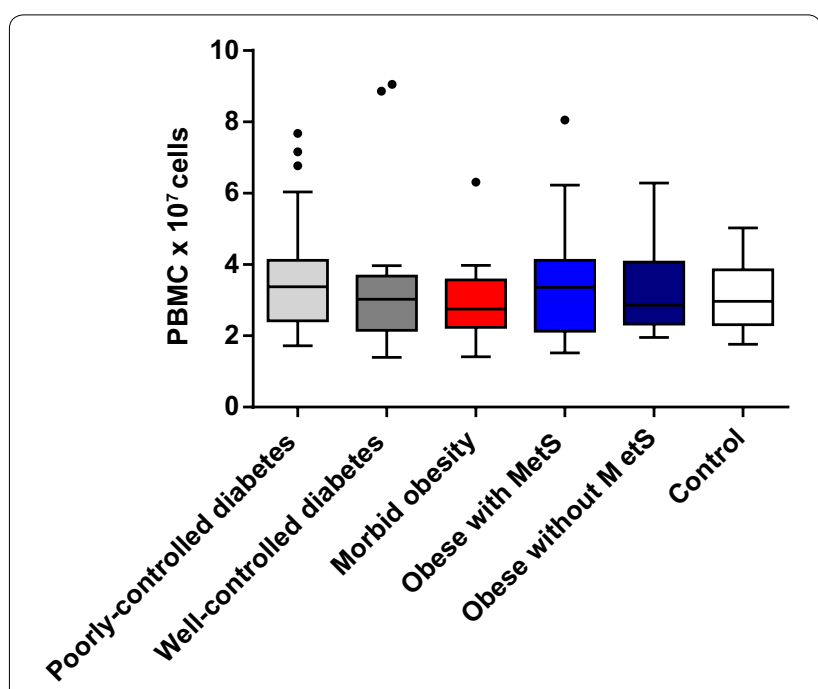

Fig. 2 Mean PBMC cell count ( $\times 10^{7}$ cells): both visits (Visit 1 and Visit 2) combined. PBMC peripheral blood mononuclear cell. The bottom and top edges of the box are located at the sample 25th and 75th percentiles and the center horizontal line is drawn at the 50th percentile (median). The whiskers extend at most 1.5 interquartile ranges

no difference in \% phagocytosis between the cohorts for any of the opsonizing agents tested. The $95 \%$ confidence interval of the \% phagocytosis for all 6 cohorts overlapped for all opsonizing agents tested (Fig. 5). These results indicate no overt differences in neutrophil phagocytic capabilities for all of the opsonizing agents tested in these subgroups. 


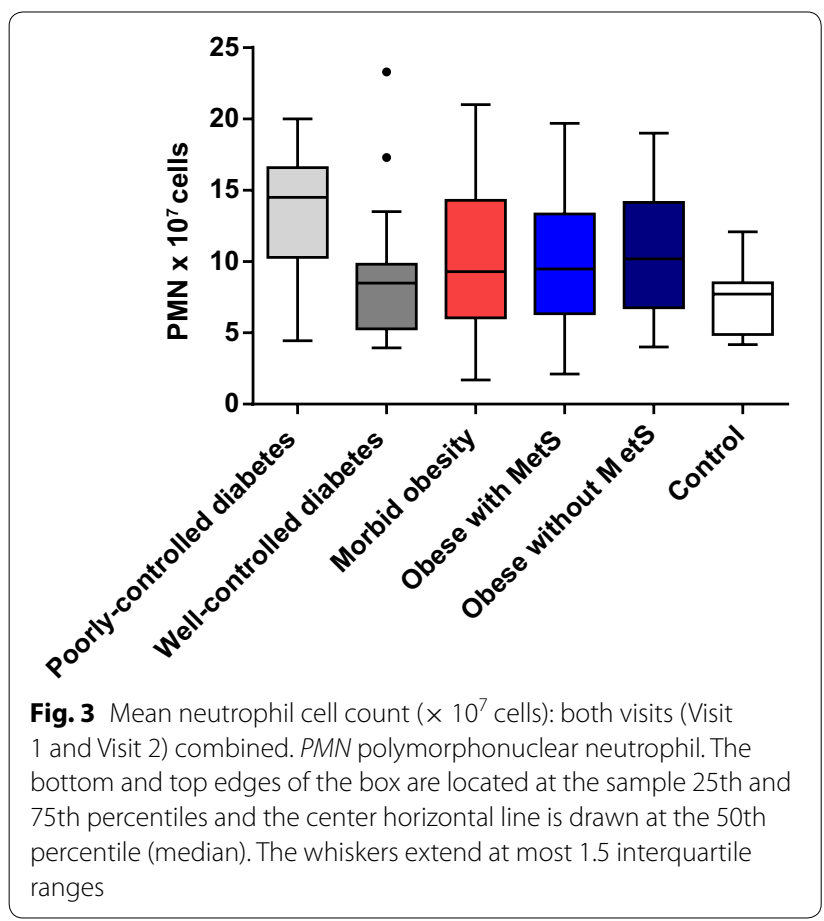

\section{Neutrophil subsets by cohort}

The average \% neutrophil subsets range at both visits was $81-91 \%$ for normal neutrophils, $2-6 \%$ for suppressors, and $3-5 \%$ for killer neutrophils. The $\%$ CD $47+$ neutrophils ranged from 99.8 to $100 \%$. The $95 \%$ CIs of the 6 cohorts overlapped for each of the neutrophil subsets and the median \% of neutrophil subsets for all 6 cohorts were also not overtly different (Table 2). These results indicate that the neutrophils from the morbid and healthy patient cohorts had similar percentages of normal (CD16 ${ }^{\text {bright }}$ CD62 $\mathrm{L}^{\text {bright }}$ ), suppressor (CD16 ${ }^{\text {bright }} \mathrm{CD}$ 62 $\left.\mathrm{L}^{\mathrm{dim}}\right)$, killer (CD16 ${ }^{\text {dim }}$ CD62 $\mathrm{L}^{\text {bright }}$, and CD47+ neutrophils.

\section{OPA titers}

OPA geometric mean titers of both visits ranged from 13,014 to 27,569 for high titered CP8 immune sera, from 1001 to 1434 for medium titered CP8 immune sera, and from 59.7 to 87.3 for low titered CP8 immune sera. The 95\% CIs of the OPA titers in the 6 cohorts overlapped irrespective of titer level (Table 3), so there was no evidence for differences in opsonophagocytosis activity among the neutrophils in all cohorts.

\section{cLIA titers}

The average cLIA titer in subjects at both visits ranged from 24.9 to 55.5 for CP5, from 50.5 to 170 for CP8, and from 36.5 to 50.6 for ClfA. The $95 \%$ CIs of the 6 cohorts overlapped for the CP5, CP8, and ClfA cLIA. cLIA scatterplots per cohort for CP5, CP8, and ClfA show no evidence for substantial differences in the median cLIA titers for all cohorts (Fig. 6), indicating that the morbid cohorts had no overt differences in pre-existing CP5, $\mathrm{CP} 8$, and ClfA titers compared with the healthy patient cohort. An increase in the interquartile range of CP5 titers was noted in the morbid obesity and the obese without MetS cohorts, although the 95\% confidence intervals were overlapping between these groups and the healthy patient cohort. There were too few subjects with an $\mathrm{rMntC}$ titer to allow for statistical analysis.

\section{Covariate results}

Neutrophil assay results were summarized for the following variables with all cohorts pooled: fasting glucose (mg/dL); HbA1c (\%); BMI $\left(\mathrm{kg} / \mathrm{m}^{2}\right)$; smoking; age; sex; CRP (mg/L); statin use; use of diabetes medication, and duration of diabetic history (days). Neutrophil function results were similar across all of these variables.

\section{Post-hoc analysis using alternative AHA/NHLBI diagnostic criteria for metabolic syndrome Subject disposition and characteristics}

In this analysis, subjects were reassigned using the alternative AHA/NHLBI MetS criteria [28]; 8 subjects who were previously assigned to the 'obese without MetS' cohort were moved to the 'obese with MetS' cohort. This shift reflected the inclusion of individuals who were on medication to correct the MetS. Using the alternative criteria, there were 28 subjects assigned to the 'obese with MetS' cohort and 12 subjects assigned to the 'obese without MetS' cohort who completed Visit 1. Thirteen subjects in the 'obese with MetS' cohort and 10 subjects in the 'obese without MetS' cohort were brought in for Visit 2 . The subject assignments to the remaining 4 cohorts were identical with those of the main analysis. The demographic characteristics for the 'obese with MetS' and the 'obese without MetS' cohorts are shown in Table 4.

The mean BMI $( \pm \mathrm{SD})$ for the 'obese with MetS' was $34.1 \pm 1.91 \mathrm{~kg} / \mathrm{m}^{2}$ and 'obese without MetS' was $34.0 \pm 3.33 \mathrm{~kg} / \mathrm{m}^{2}$. This compares with a mean BMI of $33.8 \pm 1.85 \mathrm{~kg} / \mathrm{m}^{2}$ for the 'obese with MetS' and $34.4 \pm 2.83 \mathrm{~kg} / \mathrm{m}^{2}$ for the 'obese without MetS cohort' in the per protocol analysis. The mean HbA1c level was $5.8 \%$ in the 'obese with MetS' and 5.5\% in the 'obese without MetS'. In addition to those in the 'obese with MetS' cohort, $85.7 \%$ of the subjects in the poorly controlled diabetes, $83.3 \%$ of the morbidly obese and $75.0 \%$ of the wellcontrolled diabetes cohorts were also diagnosed with MetS.

\section{Immunogenicity results}

Results for all immunogenicity parameters (PBMC/neutrophil counts, chemotaxis, phagocytosis, OPA, and cLIA 

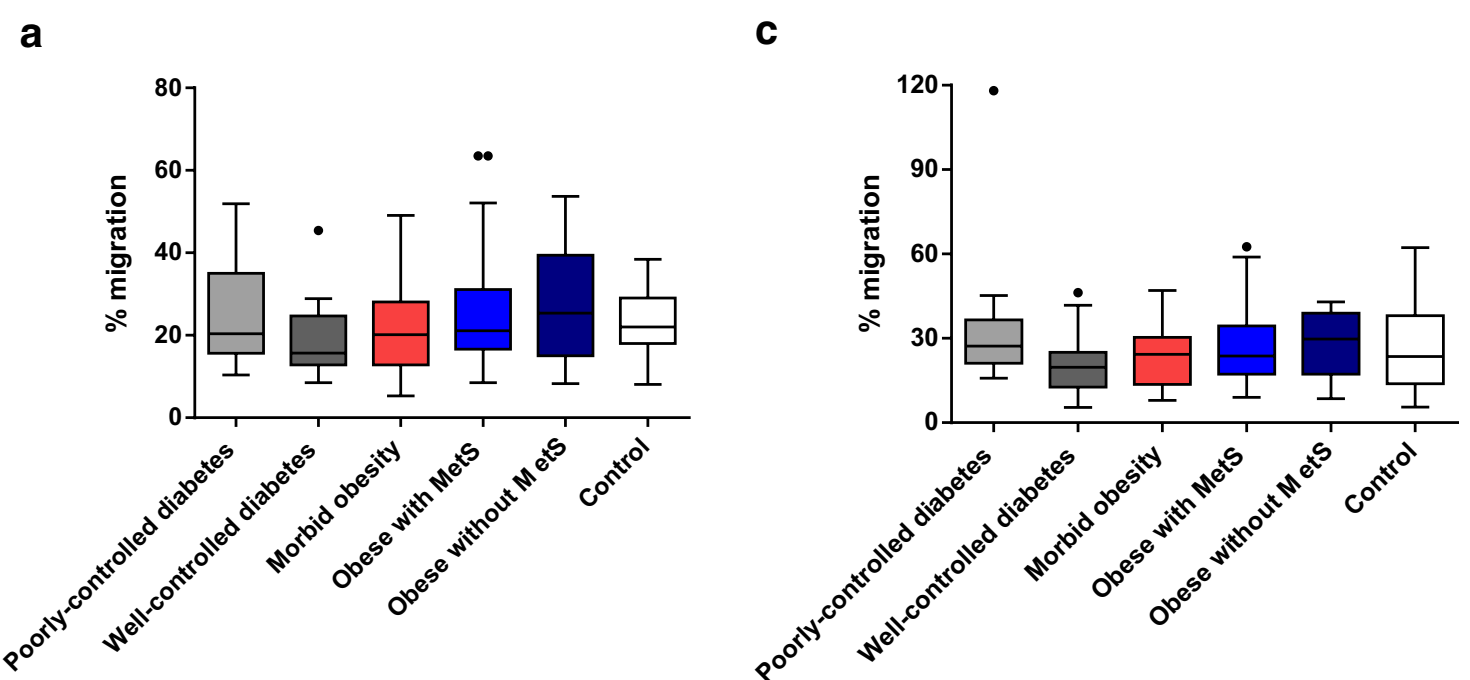

b

d
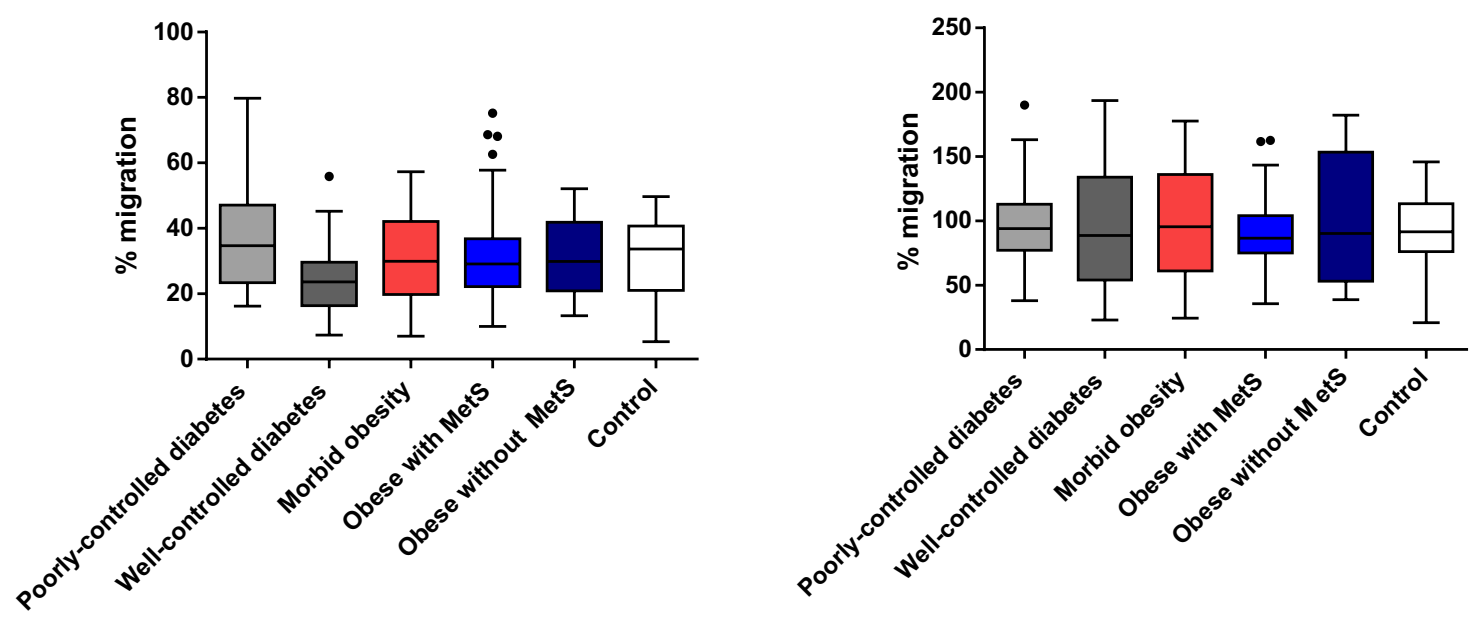

e

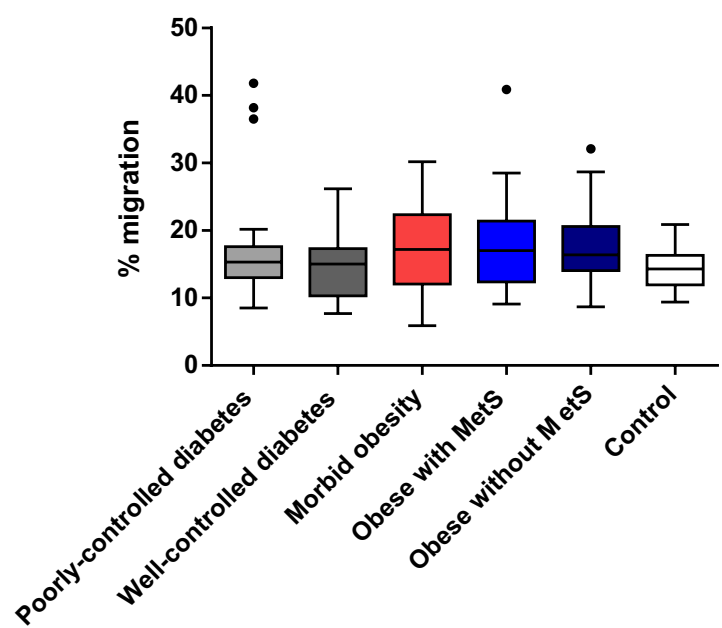

Fig. 4 Mean \% migration towards chemoattractants tested (fMLP, IL-8, C5a, FBS media) and RPMI media alone: both visits (Visit 1 and Visit 2) combined. a fMLP chemotaxis $\mathbf{b}$ IL-8 chemotaxis c C5a chemotaxis $\mathbf{d}$ FBS media chemotaxis e RPMI media chemotaxis. FBS: Fetal bovine serum. The bottom and top edges of the box are located at the sample 25th and 75th percentiles and the center horizontal line is drawn at the 50th percentile (median). The whiskers extend at most 1.5 interquartile ranges 
a

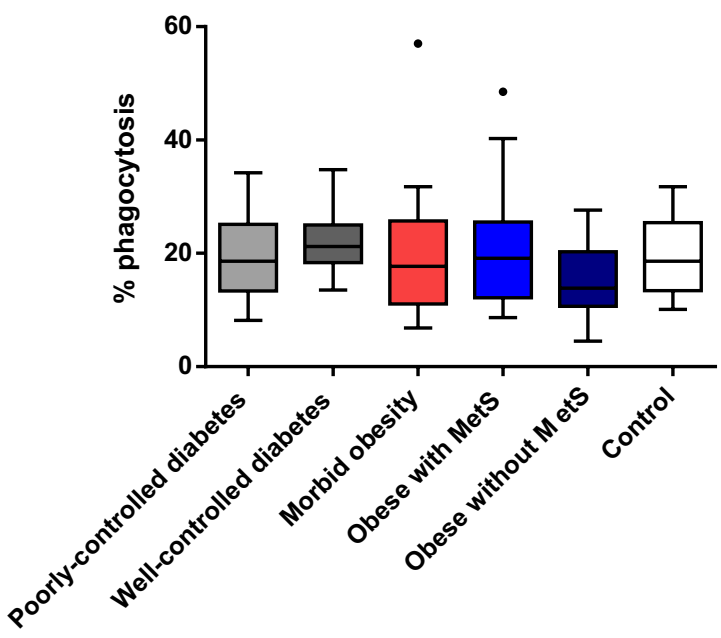

b

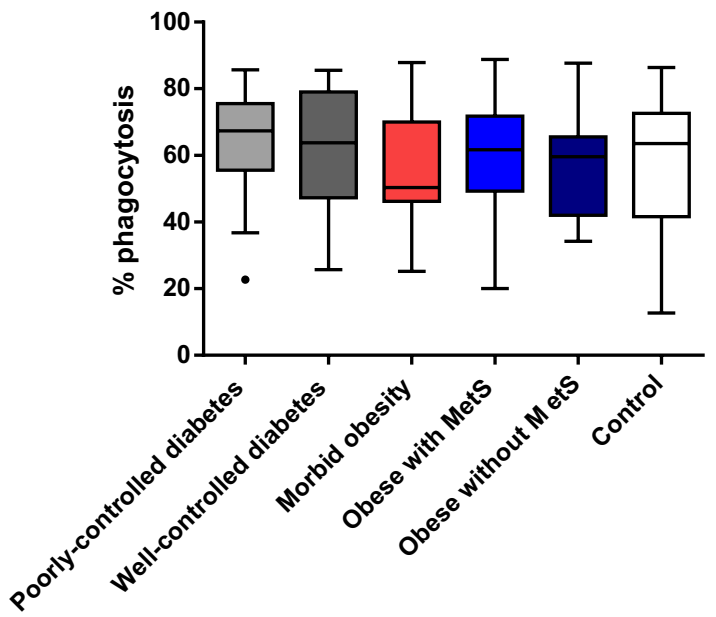

C

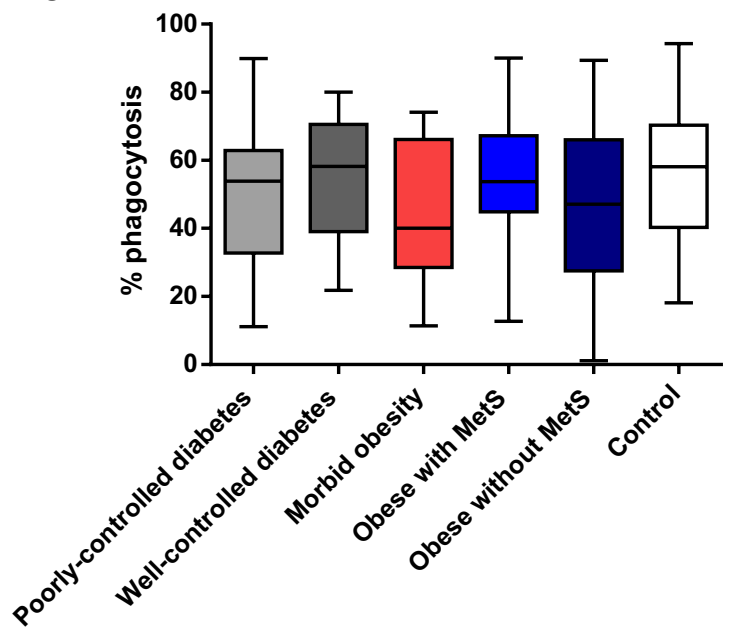

d

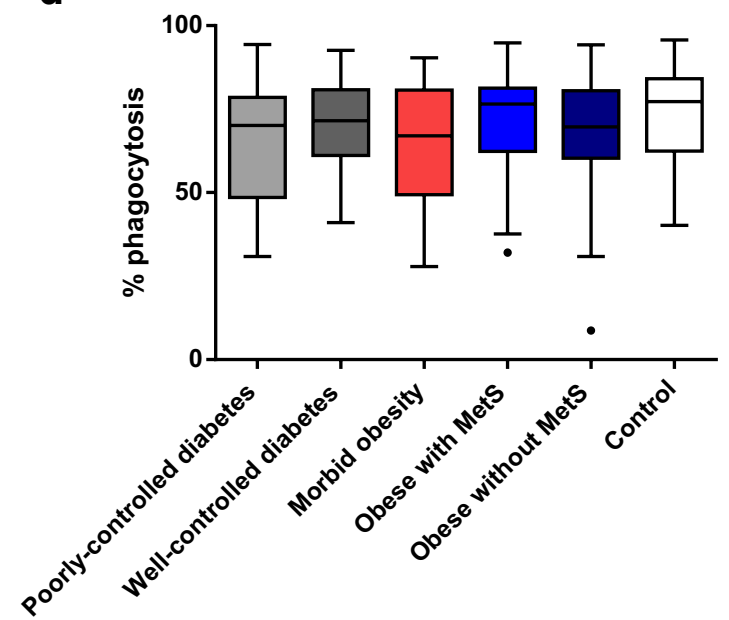

Fig. 5 Mean \% phagocytosis (neutrophil uptake of opsonized S. aureus) (no opsonization, individual plasma, normal human sera, CP8 immune sera): both visits (Visit 1 and Visit 2) combined. a No opsonization, b Individual plasma, c Normal human sera, $\mathbf{d}$ CP8 immune sera. The bottom and top edges of the box are located at the sample 25th and 75th percentiles and the center horizontal line is drawn at the 50th percentile (median). The whiskers extend at most 1.5 interquartile ranges.

titers) in the reassigned 'obese without MetS' and 'obese with MetS' cohorts were similar to the results of the per protocol analysis (data not shown).

\section{Discussion}

This exploratory clinical research study showed no measurable impairment of ex vivo function in neutrophils isolated from 78 individuals with poorly or well-controlled diabetes, obesity, or MetS, compared with neutrophils from healthy patients.

It has been suggested that chronic low-grade inflammation, which is associated with increased blood counts of neutrophils, lymphocytes, and other inflammatory markers, may be involved in the pathogenesis of obesity, insulin resistance, and diabetes [29]. In this study, there was some variability in neutrophil counts between cohorts, with a trend towards a higher number of neutrophils in obese subjects, and in those with long-term diabetes, high CRP, high fasting glucose, and high HbA1c. These differences were not statistically significant, perhaps due to the relatively small numbers per cohort, as discussed later.

Neutrophils from patients with poorly-controlled, uninfected diabetes were reported to show reduced $S$. aureus killing compared with neutrophils from patients with well-controlled diabetes or those of healthy patients [30]. The altered neutrophil phagocytosis and bactericidal 
Table 2 Neutrophil subsets (average \%) by cohort of Visit 1 and Visit 2

\begin{tabular}{|c|c|c|c|c|c|c|}
\hline \multicolumn{7}{|l|}{ Cohort } \\
\hline Neutrophil subset & $\begin{array}{l}\text { Poorly-controlled } \\
\text { diabetes mellitus } \\
(\mathrm{N}=14)\end{array}$ & $\begin{array}{l}\text { Well-controlled } \\
\text { diabetes mellitus } \\
(\mathrm{N}=12)\end{array}$ & $\begin{array}{l}\text { Morbid obesity } \\
(\mathrm{N}=12)\end{array}$ & $\begin{array}{l}\text { Obese with } \\
\text { metabolic } \\
\text { syndrome }(N=20)\end{array}$ & $\begin{array}{l}\text { Obese without } \\
\text { metabolic } \\
\text { syndrome }(\mathrm{N}=20)\end{array}$ & Control $(N=12)$ \\
\hline \multicolumn{7}{|c|}{ "Normal" (CD16 bright/CD62 bright) } \\
\hline $\mathrm{N}, \%$ RSD & $14,3.73$ & $12,7.54$ & $12,18.10$ & $20,9.11$ & $20,16.83$ & $12,6.85$ \\
\hline Mean, median & $91.2,92.3$ & $90.3,91.9$ & $81.1,84.0$ & $86.3,88.4$ & $84.0,89.9$ & $88.5,89.0$ \\
\hline $95 \% \mathrm{Cl}$ & $84.2,98.9$ & $76.5,106.5$ & $54.7,120.5$ & $71.3,104.4$ & $59.2,119.2$ & $76.1,102.9$ \\
\hline \multicolumn{7}{|c|}{ "Suppressors" (CD16 bright/CD62L dim) } \\
\hline $\mathrm{N}, \% \mathrm{RSD}$ & $14,107.5$ & $12,135.3$ & $12,150.9$ & $20,143.6$ & $20,213.2$ & $12,124.2$ \\
\hline Mean, median & $2.5,2.5$ & $2.4,2.2$ & $5.9,6.1$ & $3.4,3.2$ & $4.2,3.6$ & $2.2,1.5$ \\
\hline $95 \% \mathrm{Cl}$ & $0.4,16.9$ & $0.3,22.7$ & $0.5,65.1$ & $0.4,31.1$ & $0.3,65.1$ & $0.3,18.5$ \\
\hline \multicolumn{7}{|c|}{ "Killer" (CD16 dim/CD62L bright) } \\
\hline $\mathrm{N}, \%$ RSD & $14,82.83$ & $12,83.71$ & $12,60.22$ & $20,78.80$ & $20,55.68$ & $12,43.27$ \\
\hline Mean, median & $2.8,2.7$ & $3.1,3.1$ & $4.9,5.3$ & $4.7,5.1$ & $3.0,3.2$ & $4.7,4.9$ \\
\hline $95 \% \mathrm{Cl}$ & $0.6,13.3$ & $0.6,15.5$ & $1.5,16.8$ & $1.1,20.2$ & $1.0,8.9$ & $1.9,11.7$ \\
\hline \multicolumn{7}{|l|}{$\% C D 47+$} \\
\hline $\mathrm{N}, \% \mathrm{RSD}$ & $14,0.03$ & $12,0.44$ & $12,0.04$ & $20,0.23$ & $20,0.04$ & $12,0.01$ \\
\hline Mean, median & $100.0,100.0$ & $99.8,100.0$ & $100.0,100.0$ & $99.9,100.0$ & $100.0,100.0$ & $100.0,100.0$ \\
\hline $95 \% \mathrm{Cl}$ & $99.9,100.0$ & $98.8,100.7$ & $99.9,100.1$ & $99.4,100.4$ & $99.9,100.1$ & $100.0,100.0$ \\
\hline \multicolumn{7}{|l|}{ CD47 MFI } \\
\hline $\mathrm{N}, \% \mathrm{RSD}$ & $14,25.13$ & $12,48.26$ & $12,18.40$ & $20,17.28$ & $20,19.60$ & $12,19.80$ \\
\hline Mean, median & $18,462,16,709$ & $15,558,16,598$ & $19,060,19,857$ & $16,627,17,062$ & $17,226,16,118$ & $18,164,17,718$ \\
\hline $95 \% \mathrm{Cl}$ & $10,817,31,510$ & $5684,42,590$ & $12,757,28,477$ & $11,612,23,809$ & $11,475,25,860$ & $11,797,27,967$ \\
\hline
\end{tabular}

$\mathrm{Cl}$ confidence interval, $\mathrm{MFI}$ mean fluorescence intensity, RSD relative standard deviation

Table 3 Average OPA (titer) by cohort: both visits (Visit 1 and Visit 2) combined

\begin{tabular}{|c|c|c|c|c|c|c|}
\hline \multicolumn{7}{|l|}{ Cohort } \\
\hline Subset & $\begin{array}{l}\text { Poorly-controlled } \\
\text { diabetes mellitus } \\
(\mathrm{N}=14)\end{array}$ & $\begin{array}{l}\text { Well-controlled } \\
\text { diabetes mellitus } \\
(\mathrm{N}=12)\end{array}$ & $\begin{array}{l}\text { Morbid obesity } \\
(N=12)\end{array}$ & $\begin{array}{l}\text { Obese with } \\
\text { metabolic } \\
\text { syndrome }(N=20)\end{array}$ & $\begin{array}{l}\text { Obese without } \\
\text { metabolic } \\
\text { syndrome }(\mathrm{N}=20)\end{array}$ & Control $(\mathrm{N}=12)$ \\
\hline \multicolumn{7}{|c|}{ High titer sera } \\
\hline $\mathrm{N}, \% \mathrm{RSD}$ & $14,84.23$ & $12,54.00$ & $12,187.7$ & $18,197.2$ & $20,427.0$ & $12,89.48$ \\
\hline $\begin{array}{l}\text { Mean, } \\
\text { median }\end{array}$ & $24,968,28,580$ & $27,569,30,114$ & $13,422,20,032$ & $17,408,21,465$ & $12,036,23,405$ & $13,014,13,094$ \\
\hline $95 \% \mathrm{Cl}$ & $5133,121,462$ & $9056,83,928$ & $898,200,545$ & $1220,248,333$ & $329,440,071$ & $2406,70,391$ \\
\hline \multicolumn{7}{|c|}{ Medium titer sera } \\
\hline $\mathrm{N}, \% \mathrm{RSD}$ & $14,26.81$ & $12,85.08$ & $12,44.84$ & $20,81.37$ & $20,106.0$ & $12,25.00$ \\
\hline $\begin{array}{l}\text { Mean, } \\
\text { median }\end{array}$ & 1262,1222 & 1434,1366 & 1109,1135 & 1204, 1089 & 1224,1363 & 1001,1013 \\
\hline $95 \% \mathrm{Cl}$ & 714,2230 & 283,7276 & 432,2844 & 271,5351 & 199,7529 & 582,1722 \\
\hline \multicolumn{7}{|c|}{ Low titer sera } \\
\hline $\mathrm{N}, \% \mathrm{RSD}$ & $14,88.09$ & $12,40.61$ & $12,26.80$ & $20,93.19$ & $20,54.46$ & $12,65.10$ \\
\hline $\begin{array}{l}\text { Mean, } \\
\text { median }\end{array}$ & $87.3,66.4$ & $69.1,63.4$ & $59.7,50.0$ & $79.8,55.4$ & $77.5,66.1$ & $77.3,63.8$ \\
\hline $95 \% \mathrm{Cl}$ & $17.0,448.9$ & $29.2,163.3$ & $33.4,106.5$ & $15.2,417.4$ & $26.7,225.1$ & $20.9,286.1$ \\
\hline
\end{tabular}

Cl confidence interval, OPA opsonophagocytic assay, $R S D$ relative standard deviation 

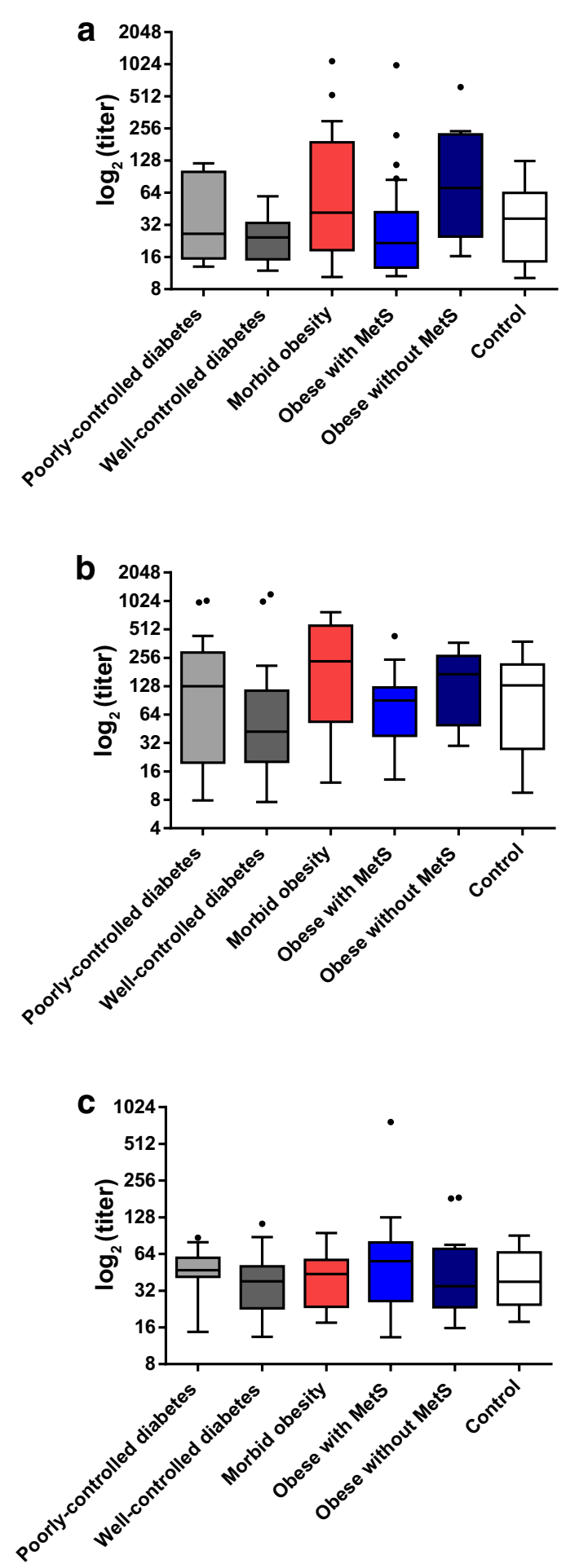

Fig. 6 Mean CP5, CP8, and ClfA competitive Luminex immunoassay (cLIA) titers: both visits (Visit 1 and Visit 2) combined. a CP5 b CP8 $\mathbf{c}$ ClfA. The bottom and top edges of the box are located at the sample 25th and 75th percentiles and the center horizontal line is drawn at the 50th percentile (median). The whiskers extend at most 1.5 interquartile ranges activity in poorly-controlled diabetes patients is thought to be associated with poor blood glucose control and may be related to the direct or indirect effects of insulin, as evidence shows that these activities can be restored by insulin administration $[16,30]$. In our study, neutrophils from all cohorts showed similar ability to migrate towards chemotactic stimuli and phagocytose and kill $S$. aureus.

A recent small study of 30 obese patients with diabetes, hyperlipidemia, and high blood pressure found the functional capacity of neutrophils from these comorbid patients to be comparable with that of lean patients, in terms of phagocytosis, chemotaxis, and superoxidegenerating capacity towards Escherichia coli [31]. No alterations in neutrophil functions were observed with differing age, gender, diabetic status, or hyperlipidemia [31]. In our study, similarly, neutrophil function was similar when grouped by sex, age, HbA1c, BMI, fasting glucose, smoking, use of statin or diabetes medication, by diabetes history, or when grouping patients using different MetS criteria (data not shown).

There were no significant differences in neutrophil subset populations or pre-existing antibody titers among all studied cohorts, as has been previously reported [12, 13]. Based on these results, a similar functional immune response to $S$. aureus antigens may be predicted in comorbid and healthy cohorts.

The main limitation of this study was that the number of patients sampled per cohort was small, which may reduce the ability to detect more subtle between-group differences in neutrophil counts and function. The lack of overt impairment in neutrophil activity seen in the comorbid cohorts in this in vitro study may differ from similar studies due to a number of factors, including study size, variability in experimental design and severity of disease, or level of diabetes control.

Reassignment of the 'obese without MetS' and the 'obese with MetS' cohorts based on the AHA/NHLBI criteria for MetS [28] showed no differences in neutrophil functional properties between the subjects with obesity and metabolic syndrome/obesity without MetS and the other cohorts, indicating that control of MetS with appropriate therapeutics does not overtly impact neutrophil function.

\section{Conclusions}

The lack of measurable impairment in in vitro neutrophil function in individuals with obesity, MetS, or diabetes predicts that an efficacious $S$. aureus vaccine able to generate robust antibody responses that can enhance neutrophil-mediated bacterial killing in healthy subjects could, in principle, be efficacious in these comorbid 
Table 4 Subject demographics for analysis using AHA/NHLBI criteria metabolic syndrome criteria affecting the obese with metabolic syndrome cohort and obese without metabolic syndrome cohort

\begin{tabular}{|c|c|c|c|c|c|c|}
\hline \multicolumn{7}{|l|}{ Cohort } \\
\hline Characteristics & $\begin{array}{l}\text { Poorly-controlled } \\
\text { diabetes mellitus } \\
(\mathrm{N}=14)\end{array}$ & $\begin{array}{l}\text { Well-controlled } \\
\text { diabetes mellitus } \\
(\mathrm{N}=12)\end{array}$ & $\begin{array}{l}\text { Morbid obesity } \\
(\mathrm{N}=12)\end{array}$ & $\begin{array}{l}\text { Obese with meta- } \\
\text { bolic syndrome } \\
(\mathrm{N}=28)^{*}\end{array}$ & $\begin{array}{l}\text { Obese with- } \\
\text { out metabolic syn- } \\
\text { drome }(\mathrm{N}=12)^{*}\end{array}$ & Control $(\mathrm{N}=12)$ \\
\hline \multicolumn{7}{|l|}{ Sex, n (\%) } \\
\hline Male & $10(71.4)$ & $6(50.0)$ & $6(50.0)$ & $18(64.3)$ & $8(66.7)$ & $4(33.0)$ \\
\hline Female & $4(28.6)$ & $6(50.0)$ & $6(50.0)$ & $10(35.7)$ & $4(33.3)$ & $8(66.7)$ \\
\hline \multicolumn{7}{|l|}{ Race, n (\%) } \\
\hline White & $10(71.4)$ & $9(75.0)$ & $9(75.0)$ & $24(85.7)$ & $10(83.3)$ & $10(83.3)$ \\
\hline $\begin{array}{l}\text { Black or African } \\
\text { American }\end{array}$ & $3(21.4$ & $3(25.0)$ & $3(25.0)$ & $4(14.3)$ & $2(16.7)$ & $2(16.7)$ \\
\hline Asian & $1(7.1)$ & $0(0.0)$ & $0(0.0)$ & $0(0.0)$ & $0(0.0)$ & $0(0.0)$ \\
\hline \multicolumn{7}{|l|}{ Ethnicity, n (\%) } \\
\hline Hispanic or Latino & $0(0.0)$ & $0(0.0)$ & $0(0.0)$ & $1(3.6)$ & $0(0.0)$ & $0(0.0)$ \\
\hline $\begin{array}{l}\text { Non-Hispanic/ } \\
\text { Latino }\end{array}$ & $14(100.0)$ & $12(100.0)$ & $12(100.0)$ & $27(96.4)$ & $12(100.0)$ & $12(100.0)$ \\
\hline \multicolumn{7}{|l|}{ Age at entry (years) } \\
\hline Mean (SD) & $60.6(7.11)$ & $64.0(8.10)$ & $57.1(8.82)$ & $58.7(9.98)$ & $48.1(9.72)$ & $60.9(11.37)$ \\
\hline Median (min, max) & $62.0(47,72)$ & $66.0(48,73)$ & $56.0(45,70)$ & $58.5(41,74)$ & $48.5(33,70)$ & $65.5(34,72)$ \\
\hline
\end{tabular}

AHA/NHLBI American Heart Association/National Heart, Lung, and Blood Institute

* Repeated analysis using AHA/NHLBI metabolic syndrome criteria [24] for obese with metabolic syndrome and obese without metabolic syndrome cohorts

populations. The safety, tolerability, and immunogenicity of the SA4Ag vaccine is currently under evaluation in patients undergoing elective spinal fusion surgery (NCT02388165).

\begin{abstract}
Abbreviations
AHA/NHLBI: American Heart Association/National Heart, Lung, and Blood Institute; BMI: body mass index; CLIA: competitive Luminex ${ }^{\circledR}$ immunoassay; CRP: C-reactive protein; FBS: fetal bovine serum; MetS: metabolic syndrome; MFI: mean fluorescence intensity; OPA: opsonophagocytic activity; PBMC: peripheral blood mononuclear cell; RSD: relative standard deviation; S. aureus: Staphylococcus aureus; SA3Ag: 3-antigen S. aureus; SA4Ag: 4-antigen S. aureus.
\end{abstract}

\section{Authors' contributions}

All authors were equal participants in the concept, design, collection and analysis of the data, and contributed to preparing the first and all subsequent drafts of the manuscript. All authors read and approved the final manuscript.

\section{Author details}

1 Pfizer Vaccine Research and Development, 401 North Middletown Rd, Pearl River, NY 10965, USA. ${ }^{2}$ Cardiovascular Research Center and Cardiology Division, Department of Medicine, Massachusetts General Hospital and Harvard Medical School, Boston, MA, USA

\section{Acknowledgements}

Medical writing support was provided by Sharmila Blows, Ph.D., of Engage Scientific Solutions, and was funded by Pfizer.

\section{Competing interests}

Annaliesa Anderson, Douglas Girgenti, Alejandra Gurtman, Kathrin Jansen, Yongdong Liu, Lisa McNeil, Stanley Mullen, Sudam Pathirana, Michael Pride, Ingrid Scully, and Christine Singer are employees of Pfizer and as such may own stock in the company. Paul Huang received grant support from Pfizer to conduct the study.
Availability of data and materials

All data generated or analysed during this study are included in this published article.

\section{Consent for publication}

All authors provided consent for this publication.

\section{Ethics approval and consent to participate}

The study was approved by the Institutional Review Board of Massachusetts General Hospital. All participants signed informed consent forms prior to beginning any study procedure.

\section{Funding}

This study was sponsored by Pfizer. Medical writing support was provided by Sharmila Blows, Ph.D., of Engage Scientific Solutions, and was funded by Pfizer.

\section{Publisher's Note}

Springer Nature remains neutral with regard to jurisdictional claims in published maps and institutional affiliations.

Received: 15 March 2017 Accepted: 25 September 2017

Published online: 03 October 2017

References

1. Jacobsson G, Dashti S, Wahlberg T, Andersson R. The epidemiology of and risk factors for invasive Staphylococcus aureus infections in western Sweden. Scand J Infect Dis. 2007;39:6-13.

2. Engemann JJ, Carmeli Y, Cosgrove SE, Fowler VG, Bronstein MZ, et al. Adverse clinical and economic outcomes attributable to methicillin resistance among patients with Staphylococcus aureus surgical site infection. Clin Infect Dis. 2003;36:592-8.

3. Befus M, Lowy FD, Miko BA, Mukherjee DV, Herzig CT, et al. Obesity as a determinant of Staphylococcus aureus colonization among inmates 
in maximum-security prisons in New York State. Am J Epidemiol. 2015;182:494-502.

4. Guo S, Dipietro LA. Factors affecting wound healing. J Dent Res. 2010;89:219-29.

5. Kabon B, Nagele A, Reddy D, Eagon C, Fleshman JW, et al. Obesity decreases perioperative tissue oxygenation. Anesthesiology. 2004;100:274-80

6. Edmiston CE, Krepel C, Kelly H, Larson J, Andris D, et al. Perioperative antibiotic prophylaxis in the gastric bypass patient: do we achieve therapeutic levels? Surgery. 2004;136:738-47.

7. Pereira MA, Sannomiya P, Leme JG. Inhibition of leukocyte chemotaxis by factor in alloxan-induced diabetic rat plasma. Diabetes. 1987;36:1307-14.

8. Delamaire M, Maugendre D, Moreno M, Le Goff MC, Allannic H, et al. Impaired leucocyte functions in diabetic patients. Diabet Med. 1997:14:29-34.

9. Marhoffer W, Stein M, Schleinkofer L, Federlin K. Evidence of ex vivo and in vitro impaired neutrophil oxidative burst and phagocytic capacity in type 1 diabetes mellitus. Diabetes Res Clin Pract. 1993;19:183-8.

10. Liberatore RR Jr, Barbosa SF, Alkimin M, Bellinati-Pires R, Florido MP, et al. Is immunity in diabetic patients influencing the susceptibility to infections? Immunoglobulins, complement and phagocytic function in children and adolescents with type 1 diabetes mellitus. Pediatr Diabetes. 2005;6:206-12.

11. O'Rourke RW, Kay T, Lyle EA, Traxler SA, Deveney CW, et al. Alterations in peripheral blood lymphocyte cytokine expression in obesity. Clin Exp Immunol. 2006;146:39-46.

12. Kamp VM, Pillay J, Lammers JW, Pickkers P, Ulfman LH, et al. Human suppressive neutrophils CD16bright/CD62Ldim exhibit decreased adhesion. J Leukoc Biol. 2012;92:1011-20.

13. Pillay J, Kamp VM, van Hoffen E, Visser T, Tak T, et al. A subset of neutrophils in human systemic inflammation inhibits $T$ cell responses through Mac-1. J Clin Invest. 2012;122:327-36.

14. Wetzler C, Kampfer H, Stallmeyer B, Pfeilschifter J, Frank S. Large and sustained induction of chemokines during impaired wound healing in the genetically diabetic mouse: prolonged persistence of neutrophils and macrophages during the late phase of repair. J Invest Dermatol. 2000;115:245-53.

15. Pierce GF. Inflammation in nonhealing diabetic wounds: the space-time continuum does matter. Am J Pathol. 2001;159:399-403.

16. Yano H, Kinoshita M, Fujino K, Nakashima M, Yamamoto Y, et al. Insulin treatment directly restores neutrophil phagocytosis and bactericidal activity in diabetic mice and thereby improves surgical site Staphylococcus aureus infection. Infect Immun. 2012;80:4409-16.

17. Shinefield H, Black S, Fattom A, Horwith G, Rasgon S, et al. Use of a Staphylococcus aureus conjugate vaccine in patients receiving hemodialysis. N Engl J Med. 2002;346:491-6.

18. Fowler VG, Allen KB, Moreira ED, Moustafa M, Isgro F, et al. Effect of an investigational vaccine for preventing Staphylococcus aureus infections after cardiothoracic surgery: a randomized trial. JAMA. 2013;309:1368-78.
19. Anderson AS, Scully IL, Timofeyeva Y, Murphy E, McNeil LK, et al. Staphylococcus aureus manganese transport protein $C$ is a highly conserved cell surface protein that elicits protective immunity against $S$. aureus and Staphylococcus epidermidis. J Infect Dis. 2012;205:1688-96.

20. Nissen M, Marshall H, Richmond P, Shakib S, Jiang Q, et al. A randomized phase I study of the safety and immunogenicity of three ascending dose levels of a 3-antigen Staphylococcus aureus vaccine (SA3Ag) in healthy adults. Vaccine. 2015;33:1846-54.

21. Frenck RWJ, Creech CB, Sheldon EA, Seiden DJ, Kankam MK, et al. Safety, tolerability, and immunogenicity of a 4-antigen Staphylococcus aureus vaccine (SA4Ag): results from a first-in-human randomised, placebocontrolled phase 1/2 study. Vaccine. 2017;35:375-84.

22. Creech CB, Frenck RWJ, Sheldon EA, Seiden DJ, Kankam MK, et al. Safety, tolerability and immunogenicity of a single dose 4-antigen or 3-antigen Staphylococcus aureus vaccine in healthy older adults: results of a randomised trial. Vaccine. 2017;35:385-94.

23. Executive summary of the third report of the national cholesterol education program (NCEP) expert panel on detection, evaluation, and treatment of high blood cholesterol in adults (Adult Treatment Panel III). JAMA. 2001;285:2486-97.

24. Bernardo J, Long HJ, Simons ER. Initial cytoplasmic and phagosomal consequences of human neutrophil exposure to Staphylococcus epidermidis. Cytometry A. 2010;77:243-52.

25. Miksa M, Komura H, Wu R, Shah KG, Wang P. A novel method to determine the engulfment of apoptotic cells by macrophages using pHrodo succinimidyl ester. J Immunol Methods. 2009;342:71-7.

26. Nanra JS, Buitrago SM, Crawford S, Ng J, Fink PS, et al. Capsular polysaccharides are an important immune evasion mechanism for Staphylococcus aureus. Hum Vaccin Immunother. 2013;9:480-7.

27. Begier E, Seiden DJ, Patton M, Zito E, Severs J, et al. SA4Ag, a 4-antigen Staphylococcus aureus vaccine, rapidly induces high levels of bacteriakilling antibodies. Vaccine. 2017;35:1132-9.

28. Grundy SM, Cleeman JI, Daniels SR, Donato KA, Eckel RH, et al. Diagnosis and management of the metabolic syndrome: an American Heart Association/National Heart, Lung, and Blood Institute Scientific Statement. Circulation. 2005;1 12:2735-52.

29. Esser N, Legrand-Poels S, Piette J, Scheen AJ, Paquot N. Inflammation as a link between obesity, metabolic syndrome and type 2 diabetes. Diabetes Res Clin Pract. 2014;105:141-50.

30. Repine JE, Clawson CC, Goetz FC. Bactericidal function of neutrophils from patients with acute bacterial infections and from diabetics. I Infect Dis. 1980;142:869-75.

31. Trottier MD, Naaz A, Kacynski K, Yenumula PR, Fraker PJ. Functional capacity of neutrophils from class III obese patients. Obesity (Silver Spring). 2012;20:1057-65

\section{Submit your next manuscript to BioMed Central and we will help you at every step:}

- We accept pre-submission inquiries

- Our selector tool helps you to find the most relevant journal

- We provide round the clock customer support

- Convenient online submission

- Thorough peer review

- Inclusion in PubMed and all major indexing services

- Maximum visibility for your research

Submit your manuscript at www.biomedcentral.com/submit
BioMed Central 